\title{
LA (RE)ESCRITURA DE LOS MÁRGENES. TRADUCCIÓN Y GÉNERO EN LA LITERATURA GALLEGA
}

\author{
Patricia Buján Otero \\ Universidade de Vigo \\ María Xesús Nogueira Pereira \\ Universidade de Santiago de Compostela
}

\section{Resumen}

A partir de una selección de traducciones de textos literarios escritos por mujeres y publicadas en diferentes plataformas, estudiamos la relación entre género y traducción en el sistema literario gallego. La selección de documentos estudiados se ha realizado atendiendo a su representatividad y significación tanto para el feminismo como para la literatura. No se trata de un trabajo exhaustivo, sino panorámico, en el que pretendemos ofrecer una visión de aquellos fenómenos y tendencias que nos parecen más relevantes.

\section{Abstract \\ "(Re-)Writing the Margin. Translation and Gender in Galician Literature"}

This paper focuses on the relationship between gender and translation in the Galician literary system given a corpus of translations of literary texts written by women and published on different platforms. The selection of the analyzed documents has been made taking into account their representation and significance both for feminism and literature. This is meant to give an overview of the most relevant trends and features.

Palabras clave: Traducción. Género. Literatura gallega.

Keywords: Translation. Gender. Galician literature. 



\section{Introducción}

La traducción y la literatura de autoría femenina, sobre todo aquella que se escribe conscientemente desde el género, son fenómenos recientes en Galicia que no han sido apenas estudiados de manera conjunta a pesar de haber suscitado interés por parte de la investigación. Nuestro trabajo no pretende abordar el tema de una manera exhaustiva sino centrada en aquellas voces de poetas, ensayistas, narradoras y autoras teatrales que se han vertido al gallego. El catálogo de autoras y obras, así como el proceso editorial, literario y personal en el que se enmarca, proporciona, a nuestro juicio, una imagen ajustada del papel que juegan el género y la traducción en la literatura gallega. Centramos por lo tanto nuestro estudio en la traducción como producto (bien sea editorial, cultural, ideológico o político), y establecemos una relación, siempre necesaria, con otras disciplinas, fundamentalmente con los estudios literarios. Para un posterior trabajo quedará un estudio de aquellas obras no traducidas o no visibilizadas, una labor realmente necesaria que evidenciaría las relaciones de poder que se establecen en nuestro sistema cultural. Como todo análisis de esta naturaleza, la perspectiva temporal es por fuerza escasa, lo que obligará tal vez a matizar y revisar en el futuro algunas de nuestras conclusiones.

Cuando von Flotow (1997: 14) hablaba de lo que significaba traducir en la "era del feminismo", mencionaba tres efectos, dos de los cuales son especialmente evidentes en el caso de la literatura gallega: por un lado, la búsqueda de escritura contemporánea de mujeres que incorporar a la cultura propia y, por otro, la recuperación de un corpus de obras "perdidas" escritas por escritoras y pensadoras importantes. Von Flotow señalaba a las traductoras como introductoras de estas obras, si bien en el contexto gallego casi siempre han sido editoras o académicas feministas las que han hecho la selección, buscado las vías de publicación (normalmente, por propuesta propia dirigida a la editorial) y asumido el trabajo de traducción. Estos dos conceptos nos pueden servir como ejes para el estudio, por lo que aludiremos a ellos a lo largo del análisis. 
Como ha sido advertido en numerosas ocasiones, la producción literaria de las mujeres se ha desarrollado en un contexto de marginalidad, derivado del papel asignado al género femenino en la sociedad. Contra la falta de visibilidad de autoras y obras ha venido reaccionando en las últimas décadas el feminismo, mediante la reivindicación de figuras olvidadas y la asunción de un trabajo de planificación. Al amparo de los discursos feministas surgieron una serie de voces que cultivaron los distintos géneros, principalmente el poético, remarcando con frecuencia en la escritura su condición femenina. Estas autoras, unidas en ocasiones por un sentimiento de sororidad intergeneracional, han tenido que sortear los escollos del patriarcado desmontando verdades que se creían universales, conquistando espacios y derribando no pocos prejuicios. Tal panorama sitúa la incorporación de obras de escritoras femeninas procedentes de códigos ajenos en una encrucijada marcada por una doble marginalidad: la de la traducción y la del género.

Queremos advertir que si centramos el estudio exclusivamente en la traducción literaria es por varias razones: por su visibilidad y su capacidad visibilizadora, por su trascendencia dentro de la cultura de llegada ${ }^{1}$ y por las posibilidades que ofrece de estudio de comportamientos ideológicos. Queremos, no obstante, destacar el hecho de que en el ámbito profesional es indiscutible la presencia mayoritaria de traductoras e intérpretes ${ }^{2}$ y de que faltan más estudios acerca de comportamientos traductivos sobre género en lo que se acostumbra denominar traducción comercial o pragmática.

\section{Una historia necesaria}

El desarrollo de la traducción en Galicia y, en concreto, el estudio de conceptos como "traducir como mujer" o "políticas de traducción y feminismo", se encuadran dentro del panorama que Valado tan acertadamente describe con las siguientes palabras:

Inda que se inicia unha introdución masiva da edición de libro de texto en galego, dado que o galego quedou lexislado como vehículo e obxecto de estudo nos diversos niveis educativos, así como de traducións infantís e xuvenís, o mercado editorial segue amosando carencias debido ao baixo consumo do libro galego e ao escaso índice de profesionalidade. (2008: 10)

1. Aunque no siempre con la etiqueta "traducción", pero sí como "literatura extranjera".

2. Así, por ejemplo, podemos destacar en el ámbito profesional gallego que de los 40 socios con categoría profesional que constituyen la Asociación Galega de Profesionais da Tradución e da Interpretación, solo 7 son hombres frente a 33 mujeres (vid. http://www. agpti.org/galego/asoc_gal.php; estado: junio de 2010). 
A esto habría que sumar lo señalado por Gómez Clemente:

a pesar de que los primeros años de este siglo han sido realmente prometedores para la consolidación de la práctica traductora en Galicia, la situación no es la ideal. Hace falta una mejor planificación editorial de la traducción para llenar los vacíos que aún hay en las distintas áreas de conocimiento y para evitar el desequilibrio que existe entre los títulos publicados un año y otro. (2009: 442)

La historia reciente de la traducción al gallego se inicia en el período que marca la aprobación en el año 1983 de la Ley de Normalización Lingüística. ${ }^{3}$ El aumento de traducciones (un 200\% de la etapa 1981 a 2000, según señala Gómez Clemente 2009: 440) se debe fundamentalmente al mayor dominio de las lenguas extranjeras, a la aparición de nuevas empresas editoriales y a la fuerte demanda de literatura infantil y juvenil y de clásicos en gallego por la incorporación del gallego a la enseñanza (a raíz precisamente de la citada ley). En el año 1984 se funda la Asociación de Tradutores Galegos, entre cuyos objetivos se encuentra intentar establecer criterios que sirvan para definir una política de traducciones adecuada a las necesidades de Galicia, y en el año 1996 sale la primera promoción de licenciadas y licenciados en Traducción e Interpretación de la Universidad de Vigo, que puso a disposición del mercado por primera vez profesionales formados específicamente para traducir de otras lenguas al gallego. El perfil de la traductora y traductor de los años anteriores respondía en muchos casos a los del académico o docente que realizaba este trabajo aparte de su principal actividad económica, normalmente por voluntarismo ideológico, y que poco a poco fue ganando visibilidad y "educando" al mundo editorial e institucional gracias a la labor de una asociación como la citada. La presencia de los nuevos profesionales, conscientes de cuáles son sus derechos y obligaciones, capaces de ofrecer plazos de entrega competitivos (ya que viven de ejercer esta profesión), contribuye a profesionalizar aún más el sector.

En términos valorativos, el panorama de la edición de literatura traducida al gallego puede ser resumido de la siguiente manera. Como aspectos negativos, cabe destacar que la literatura traducida en gallego se encuadra, por una parte, en el bajo consumo de literatura extranjera en esta lengua (que debe competir además con las traducciones al español) y en la aún deficiente planificación editorial. Como aspectos positivos, conviene destacar la disponibilidad de cada vez más profesionales formados específicamente para

3. Para una panorámica histórica (desde la Edad Media hasta la actualidad) de la traducción literaria al gallego, vid. Gómez Clemente 2009; para una panorámica completa actual, vid. Luna Alonso 2007. 
la traducción al gallego y con un mayor abanico de idiomas desde los que traducir, así como el interés creciente y el esfuerzo editorial (no siempre con el apoyo institucional necesario) por ofrecer obras de autores contemporáneos.

\section{Traducción, edición y mercado: tipología de traducciones}

Uno de los síntomas que evidencian la anormalidad de la traducción literaria a la lengua gallega es su heterogeneidad desde el punto de vista de la publicación. Aunque cada vez más las editoriales planifican con cierta coherencia su catálogo de traducciones (fundamentalmente, en el género narrativo), una buena parte de las llevadas a cabo a lo largo de las últimas décadas procede de un interés personal y de una actitud voluntarista, al margen en ocasiones de cualquier perspectiva de publicación. La elección de textos obedece en este caso a criterios subjetivos que, para los estudios literarios y culturales, proporcionan muchas veces datos valiosos sobre fuentes y referentes intertextuales. Tal libertad a la hora de seleccionar los textos que van a ser producidos se da, por razones obvias, en publicaciones periódicas y también en empresas editoriales de reducido tamaño, que mantienen una mayor independencia respecto al mercado. Sobre esta cuestión llamaba la atención Luna Alonso cuando explicaba, valiéndose de los presupuestos teóricos de Bourdieu, como

non se importa o mesmo desde unha editorial de gran poder comercial, onde a importación pode resultar feita por criterios e fins comerciais, que desde o campo de produción restrinxido, onde a importación pode ter máis razóns literarias, ou desde o campo político nacionalista, onde a importación resulta con máis funcións políticas. (Luna 2006: 191)

La diversidad que se aprecia tanto en la génesis como en la difusión de las traducciones impide abordar esta cuestión de una manera general. Desde el punto de vista institucional -empleamos aquí este término en sentido amplio, para referirnos también a la cuestión editorial- es posible identificar en las traducciones literarias al gallego la siguiente tipología, que emplearemos como guía a lo largo del estudio.

- Traducción privada

- Traducción difundida a través de publicaciones periódicas

- Traducción editorial

- Traducción institucional

\section{La traducción privada}

Denominamos traducción privada a aquel ejercicio de traslación que se lleva a cabo de una manera particular y sin el objetivo inmediato de su publicación. 
En general, se trata de textos sueltos que rara vez ven la luz como tales. Muchos derivan de lecturas motivadas por intereses y gustos personales, que conforman el humus de una poética individual, grupal o incluso generacional. En este sentido, las autoras y autores traducidos se convierten, cuando tales versiones trascienden, en importantes indicadores estéticos y en claves para la interpretación de una obra. Álvaro Cunqueiro, uno de los traductores más anárquicos de la historia de la literatura gallega, hacía, respecto de la presencia de François Villon en su obra, una afirmación que nos parece esclarecedora: "Yo tengo un Villon entero en lengua gallega, que me lo fui haciendo poco a poco, para mejor leer y entender a lo largo de los años" (Armesto Faginas [1987] 1991: 71).

La trascendencia de estas lecturas-traducciones puede producirse de manera indirecta, como ocurre en el mencionado caso de Álvaro Cunqueiro, o, centrándonos en la obra de las traductoras, en el siguiente comentario de Ana Romaní, procedente de su laudatio a Marilar Aleixandre con motivo del homenaje brindado por la Asociación de Escritores en Lingua Galega:

"Eu fun unha delas". É un verso de Anne Sexton dunha tradución inédita que dun seu poema fixo Marilar Aleixandre. (Romaní 2010)

El interés suscitado por la poesía de Anne Sexton entre las poetas implicadas en la construcción de un discurso literario de género queda patente en la explicación de Romaní, que se confiesa también traductora del citado poema:

Coincidiramos Marilar Aleixandre e eu mesma na necesidade de verter ao galego este poema de Sexton, eu para unha intervención poética contra a levidade, ela nese labor necesario de tradución que mantén de Rowling a Lewis Carrol pasando por Sandra Cisneros.

Un labor recoñecido recentemente pola Asociación Galega de Tradutores. Agardo por certo con necesidade, as súas traducións de Anne Sexton, de Silvia Plath, de Adrianne Rich, e outras poetas á luz das que se ampliarán as lecturas críticas sen dúbida da obra dalgunhas poetas galegas contemporáneas. (ib.)

El comentario revela la existencia de dos traducciones inéditas de la composición de Anne Sexton. Una de ellas surge con una finalidad pragmática, como es su utilización en la performance Catro poetas suicidas. Intervención poética contra a levidade (2002); la otra, por el reconocido oficio de traductora, que llevó a Marilar Aleixandre a versionar también composiciones de Silvia Plath y Adrianne Rich. Especialmente relevante nos parece la observación final acerca de la importancia de la publicación de las traducciones de las autoras mencionadas a la hora de interpretar algunas voces actuales cuya poética se ha visto influida por ellas, entre las que se incluye la propia Ana Romaní cuando se refiere a Sexton como "esa autora á que Marilar me abriu camiño nunha 
paixón compartida por esa escrita revirada" (ib.). El fragmento de la laudatio que acabamos de reproducir constituye también una muestra de las carencias existentes en el catálogo de obras traducidas, así como de las dificultades a la hora de publicar traducciones de poesía, incluso de autoras reconocidas.

Las traducciones privadas se manifiestan en otras ocasiones mediante la cita a modo de epígrafe. En este sentido, resulta interesante observar la evocación de algunas voces feministas por parte de las escritoras gallegas a modo de reivindicación, cuando no de diálogo con la composición o composiciones a las que preceden. ${ }^{4}$ Un ejemplo claro lo encontramos, por no abandonar el terreno de la poesía, en las citas que encabezan el libro Das últimas mareas, de Ana Romaní:

Todo se derruba con estrondo,

eu canto.

Edith Södergran

Os verdadeiros poemas fuxen

Emily Dickinson

(Romaní 1994)

Más allá del espíritu feminista que impregna el libro, la autora convoca a las escritoras citadas junto con Rosalía de Castro en una composición de claro contenido metapoético:

...ROSALÍA DE CASTRO, EMILY DICKINSON, EDITH SÖDERGRAN...

Procuramos no fondo da entraña

tódalas sombras da pantasma,

o desterro da bruxa...

a soidade da princesa...

a derrota da amazona...

Deixamos pegadas de sangue

nas alleas terras da palabra. (1994: 50)

Por otra parte, también Adrienne Rich, Ana Akhmátova ${ }^{5}$ y Sylvia Plath aparecen, en versión gallega, en los epígrafes de Marilar Aleixandre. En el caso de esta última, sus versos ${ }^{6}$ anticipan el motivo del veneno en el libro titulado precisamente Catálogo de velenos. Igualmente significativo resulta el epígrafe

4. Se trata de "funciones indirectas derivadas de la importancia del autor citado" (Genette 1987: 145).

5. El texto de Akhmátova, que precede el poemario Mudanzas, resulta sumamente significativo si tenemos en cuenta que el libro es una reinterpretación desde una óptica femenina y feminista de algunos pasajes de las Metamorfosis de Ovidio, y que todos los poemas están encabezados por una cita de esta obra.

6. "¿Chegou como unha frecha, chegou como un coitelo? / ¿cal dos velenos é?" y "¿Ou terei que traerche o son dos velenos?". 
de Héléne Cixous ${ }^{7}$ traducido al gallego que encabeza el poema "Asilar", del libro Fóra de min, de María Xosé Queizán.

La apropiación de textos traducidos en las citas no solo es una práctica bastante extendida en la expresión poética. También en la narrativa es posible encontrar algunos ejemplos significativos en cuanto a la selección de autoras, como el epígrafe que precede a Benquerida catástrofe (2007), de Teresa Moure. La autora elige para encabezar una novela que trata, como se anuncia en la cubierta posterior, de la reconstrucción de la identidad sexual de los personajes, una cita de Judith Butler versionada al gallego:

O xénero non pode interpretarse como unha identidade estábel senon, máis ben, como unha entidade debilmente construída no tempo, instituída nun espazo exterior mediante unha recepción estilizada de actos.

O xénero en disputa, Judith Butler

Otro tanto se podría decir del ensayo feminista, donde las autoras reivindican a menudo en sus citas voces anteriores llevando a cabo traducciones al gallego elaboradas por ellas mismas. De este modo, Carmen Blanco echa mano de un extenso fragmento de la pensadora italiana Luisa Muraro para encabezar su obra O contradiscurso das mulleres. Historia do feminismo, manteniendo, eso sí, la voz affidamento por su generalización por parte de algunas teóricas del feminismo, lo que puede entenderse como el intento de consolidar una lengua gallega de especialidad -la del pensamiento feminista-:

É o camiño que (...) chamamos "affidamento", o camiño da relación na con-

fianza, o camiño da autoridade distinta do poder, da que temos certeza gra-

cias á antiga relación coa muller que nos deu a vida e a palabra. (1995: 21)

Sea cual sea la lengua de origen, que rara vez se explicita en el paratexto, ${ }^{8}$ lo que parece quedar demostrado es la voluntad de traducir algunos textos emblemáticos de la literatura escrita por mujeres y de la literatura feminista por parte de nuestras escritoras para incorporarlos, a modo de citas, a sus obras.

Otra modalidad a la hora de visibilizar traducciones privadas consiste en su incorporación al texto, en un ejercicio de intertextualidad y collage que no resulta ajeno a las poéticas de las últimas décadas. Es el procedimiento que Chus Pato pone en práctica en una composición de Charenton en la que introduce un fragmento del poema "Keine Delikatessen", de Ingeborg Bachmann, identificado mediante la cursiva:

7. "Haberá un máis alá no que a outra / xa non será condenada a morte".

8. Una excepción la consituye Marilar Aleixandre, que en alguna de sus citas nos ofrece las versiones originales inglesas seguidas de su traducción. 
no que fai á guerra fría e ao período de máxima tensión

este poema de I. Bachmann/ "Keine Delikatessen"

[...] aprendín a ser sensata

coas palabras

que hai

(para a clase máis baixa)

fame

deshonra

tebras (...).

(Que sexa. Que sexan os outros.)

A miña parte, que se perda.

(Pato 2004: 15-16)

Las versiones gallegas de las citas alternan con textos reproducidos en su lengua original. En ocasiones, las menos, la autora proporciona los textos original y traducido. La libertad a la hora de elaborar estas traducciones privadas confluye con la voluntad de estilo en Cuarto de outono, donde María do Cebreiro hace el siguiente comentario:

Este libro, ao seu xeito, tenta probar que non debería haber propiedade no uso da palabra. Por iso, case todas as citas que se inclúen presentan desvíos significativos con respecto ao orixinal. (2008: 109)

\section{La traducción en publicaciones periódicas}

Las particulares circunstancias históricas en las que se ha desarrollado la cultura gallega y, en especial, la literatura hacen que no resulte posible comprender sus claves sin tener en cuenta el papel desarrollado por las publicaciones periódicas. Las revistas, de diferente naturaleza y muchas veces de vida efímera, han suplido a lo largo de los años el deficiente tejido editorial, por lo que constituyen un corpus, amplio y disperso, de gran valor para el conocimiento de determinados períodos de la literatura gallega, como es el caso del movimiento de renovación poética producido a comienzos de la década de los ochenta.

Algunas de las publicaciones periódicas más estables de las últimas décadas han sido receptivas a la traducción e incluso le han dedicado secciones fijas. La incorporación de la traducción literaria ha servido no solo para dar visibilidad sino también para naturalizar un hábito y para evidenciar carencias. Estas versiones presentan algunas características derivadas del propio medio. Se trata casi siempre de textos que resultan de un trabajo voluntario llevado a cabo la mayoría de las veces por escritoras y escritores. Al tratarse de iniciativas individuales, que rara vez responden a una planificación, muestran 
intereses particulares, afinidades y, en general, una voluntad de paliar la carencia de traducciones literarias al gallego. Las limitaciones de espacio condicionan además la elección de los textos, en su mayoría poéticos, aunque también, en menor medida, narrativos.

En lo que respecta a la relación entre la traducción y el género, las revistas aportan, por las razones citadas, una información de gran valor. El análisis de las principales publicaciones periódicas de las últimas décadas que dedican espacio a la traducción revela la ausencia, salvo pocas excepciones, de traducciones de escritoras.

Una de las revistas que abrió sus páginas a la traducción fue Dorna. Expresión poética galega, fundada en 1981 y publicada, con interrupciones, hasta el día de hoy. A partir de su número 6 acogió de manera esporádica versiones literarias de textos poéticos, a los que dedicó a partir del número 15 la sección "Voces de fóra". La crítica destacó el papel de Dorna en la difusión de la poesía de los ochenta, cuya tendencia más canonizada se caracterizó por la vuelta a los temas clásicos, el cuidado de la forma y, sobre todo, el culturalismo y la práctica de la intertextualidad con escritores de la literatura universal, eligiendo algunos autores de cabecera como Rilke, Ezra Pound, T. S. Elliot o Cavafis. En ese contexto deben ser entendidas muchas de las traducciones aparecidas en las páginas de la revista firmadas casi todas ellas por poetas: Rilke (Xosé María Díaz Castro), Walt Whitman (Ramiro Fonte), Cesare Pavese (Darío Xohán Cabana) o Cavafis y otros poetas griegos del siglo XX (Andrés Pociña y Mosjos Morfakidis).

Durante la década de los ochenta, el número de escritoras versionadas al gallego en las páginas de Dorna es significativamente menor: Louise Labé (Daponte y Ramón Fernández Reboiras), Sylvia Plath y Almudena Guzmán (Luisa Castro). De las tres traducciones, la de la poeta estadounidense, publicada en el número 11 (1987), posee una especial relevancia debido a la influencia que, como más arriba quedó demostrado, tuvo en algunas poetas gallegas. Luisa Castro, una de las pocas traductoras que aparecen en la revista, junto con Xela Arias y, más adelante, Ursula Heinze, vierte al gallego fragmentos del poema "Lesbos", del libro Ariel. Después de un impasse de tres años, en 1995 comienza una segunda etapa de Dorna en la que participan numerosas escritoras y escritores de la promoción conocida como dos noventa, que en general se decantó por un verso menos culturalista y por la construcción de poéticas de género, mayoritariamente femeninas. Esta última característica no tuvo, sin embargo, su reflejo en un incremento de la presencia de mujeres traducidas en las páginas de la revista. 
La situación que acabamos de describir es muy semejante a la de la revista Nordés, dirigida a partir de 1980 por la poeta Luz Pozo Garza y en cuyas páginas encontramos traducciones de Jacques Prevert (González Garcés), Robert Wells (Eduardo Moreiras) o Cesare Pavese (la propia escritora).

Un caso diferente es el que encontramos en las páginas de la revista Festa da palabra silenciada, fundada en 1983 por María Xosé Queizán. La publicación, de signo feminista, sirvió de plataforma para visibilizar la producción literaria de las escritoras gallegas y logró aglutinar voces de diferentes generaciones. En sus páginas acogió también traducciones de escritoras (el género es en este caso un criterio de selección). En el número 6 (1986) aparecían dos poemas de Sylvia Plath en versión de M. P. Aleixandre (Marilar Aleixandre). A una breve nota biográfica sigue una explicación que evidencia la oportunidad de traducir a la poeta estadounidense debido a la inaccesibilidad de sus obras:

A única obra traducida até agora ó portugués ou ó castelán -aparte da correspondencia coa súa nai- é a novela autobiográfica The Bell Jar (A Campá de Cristal) (1963) que reflexa os problemas de equilibrio mental que marcaron toda a súa vida. (Aleixandre 1986: 163)

En la Festa vieron también la luz cuatro poetas canadienses: Rhea Tregebov, Nicole Brossard, Louise Cotnoir y Di Brandt, que coincidieron, tal como se explica en una nota aclaratoria, en un evento:

A IV Feira do Libro Feminista, celebrada na primavera de 1990 en Barcelona, vai facer que estas catro poetas canadianas -traducidas ao catalán, castelán e agora ao galego- se encontrasen en Barcelona xusto cando se produciu o movemento contestatario "Meech Lake", que significou unha crise de identidade nacional que aínda continúa. (Tregebov 1991: 134)

Como podemos comprobar, la nota reproducida hace también hincapié en la oportunidad de la traducción, de la que se encargaron Marilar Aleixandre y María Xosé Queizán.

La revista acogió versiones de otras escritoras que, en algún caso, anticipaban traducciones de mayor envergadura. Es el caso de Sandra Cisneros, de quien Marilar Aleixandre trasladó al gallego tres poemas y, posteriormente, la obra Muller ceiba (1997). En la nota que acompaña estos textos, la traductora destaca la condición inédita de los poemas que verían la luz por vez primera en su versión gallega:

Ante a nosa petición de poemas para publicar na Festa da Palabra Silenciada, Sandra Cisneros tivo a xentileza de enviarnos os tres que aparecen a continuación, e que pertencen ó seu próximo libro Loose Woman, que será publicado na primavera de 1994. (Aleixandre 1994: 142) 
Festa da palabra silenciada integra por lo tanto la traducción en sus contenidos heterogéneos aglutinados en torno al género.

Otra interesante muestra para el estudio de la traducción y el género nos lo proporciona la revista A trabe de ouro, fundada en 1999 por Xosé Luís Méndez Ferrín. La publicación reserva a la versión de textos al gallego una sección en la que nuevamente encontramos un claro predominio de las voces masculinas. Entre los escritores seleccionados se encuentran algunas voces que constituían referentes para la poesía gallega: Ezra Pound (Xosé Luís Méndez Ferrín y Marta Carracedo), Seamus Heaney (Manuel Outeiriño) o Paul Celan (Michaela Kuchenreuther y Manuel Luis Stiller). La proximidad parece el criterio seguido en el fragmento del Roman de Ponthus (Anxo Fernández Ocampo), más adelante traducida de manera íntegra con el título $O$ reiciño de Galicia (1998, Henrique Harguindey). La nómina de poetas versionados en A trabe de ouro parece remitir sin embargo a un canon diferente al constituido en Dorna, como indican las versiones de Dylan Thomas (Mara Pérez Pereiro), Allen Ginsberg (Daniel Salgado) o Bertold Brecht (Catuxa López Pato). Estos ejemplos muestran, por otra parte, la incorporación significativa de traductoras. Sin embargo, la presencia de escritoras sigue siendo muy escasa: Ilse Aichinger (Rosa Marta Gómez Pato), Erin Moure (Lola Rodríguez) y Adrienne Rich (Daniel Salgado). La autora estadounidense, reivindicada por Ana Romaní y citada por Marilar Aleixandre, aparece traducida al gallego por un poeta que la presenta desde un prisma feminista, después de recoger algunos juicios acerca de su figura:

O poeta John Ashbery describiuna como "unha case de Emily Dickinson dos arrabaldes". Winston Hugh Auden prologou o seu primeiro libro -A change of world (Unha mudanza de mundo)- en 1951. Para Harold Bloom, ese señor impertinente de pelo esbrancuxado, Adrienne Rich non é máis ca unha "feminista marxista histérica", ou cousa así. Pero, mentres o patriarcado das letras estadounidenses teima en cercar a obra e a persoa de Rich, a poeta de Baltimore tece unha aventura literaria con paraxe final na fuxida do asedio masculino. (Salgado 2004: 79)

Por otro lado, Salgado destaca la oportunidad del texto seleccionado, "Tempo norteamericano", del libro Your native land, your life, explicando como

os versos da Rich acaen nestes días do Imperio a máis meter: "Todo o que escribimos / será usado contra nós / ou contra quen amamos". (Salgado 2004: 80)

Los versos escogidos por el poeta son precisamente aquellos que Marilar Aleixandre traducía para incorporarlos, como cita, a su poemario Catálogo de velenos. Lejos de ser textos anecdóticos, las traducciones publicadas en 
revistas revelan asimetrías del sistema literario y ayudan a construir cánones y repertorios.

\section{La traducción editorial}

La traducción editorial se enmarca dentro del contexto que brevemente señalamos anteriormente en el apartado "Una historia necesaria". Estudiamos en esta sección la relevancia en lo que al género se refiere de una colección específica de autoras, As Literatas, y de otras traducciones, en formato libro o electrónico, de obras significativas pero encuadradas dentro de colecciones más amplias (clásicos, narrativa actual, etc.). Conviene tener presente que, aparte de aquellas colecciones de narrativa contemporánea donde la selección de autores y autoras nace, en muchos casos, de la propuesta de un agente literario y la selección se realiza teniendo en cuenta el carácter de bestseller de la obra (presencia del libro o del autor en el mercado editorial internacional) o el carácter exótico de la lengua desde la que se traduce, ${ }^{9}$ la selección de autoras no responde en todos los casos a una política editorial consciente, sino más bien a la idea de recuperar aquellas obras escritas por mujeres que se han "perdido" en el patriarcado (von Letow 1997: 30), ${ }^{10}$ de incorporar nuevas voces y de servir de plataforma de denuncia de desigualdades y violencias.

Para la obtención de datos sobre ideologías subyacentes y presentación de las obras centramos nuestra atención en los paratextos verbales y, por ende, en la "paratraducción", entendiendo por tal el conjunto de paratextos y actividades que acompañan al texto editorial traducido:

Cando as editoriais escollen os títulos e as imaxes da cuberta do libro están a seguir unha estratexia comunicativa inzada de ideoloxía. Esa escolla determina unha recepción, unha lectura-ideolóxica-, e ata apunta o tipo de público ao que vai dirixido. Tamén pode espectacularizar por medio desas imaxes ofrecendo tamén deste xeito, adscrición xenérica, contido e argumento do libro. (Garrido 2005: 36)

9. Y, por lo tanto, enriquecedor para la cultura meta, así como con valor simbólico por representar una independencia con respecto al sistema de traducciones literarias para el español.

10. "Feminists point out that the patriarchal canon has traditionally defined aesthetics and literary value in terms that privileged work by male writers to the detriment of women writers; as a result, much writing by women has been 'lost'. This is true of the twentieth century, even though recent feminist activism has integrated many women writers into literary histories. It is more particularly true of women writers from earlier periods, whose Works need to be unearthed by literary historians and read again by literary critics. Translating has begun to play an important role in making available the knowledge, experiences and creative work of many of these earlier women writers" (von Flotow 1997: 30). 
Responsables de estos peritextos son casi siempre otros mediadores (en el caso que nos ocupa, sobre todo las editoras y las directoras de las colecciones), excepto en el caso de las notas y en las notas previas de las traductoras. El estudio de estos metatextos, como una de las estrategias que González (20012002: 113-114) señala como forma de visibilización propia y de la significación del texto que traducen, queda para un posterior estudio. Además, como aduce Castro:

un examen íntegro del proceso de traducción revela que éste no concluye con la reescritura traductora, sino que existe un espacio intermedio entre esta reescritura (traducción) y la presentación final de la obra traducida en la sociedad meta (paratraducción), donde también operan unas relaciones de poder. (2009: 253)

De nuevo, tendremos que posponer este estudio necesario, y complejo por cuanto ideológico, sobre qué se dice y no se dice en los paratextos elaborados para las obras de ciertas autoras. ${ }^{11}$

Sin pretender desmerecer la relevancia que tienen dentro del sistema literario gallego colecciones actuales de traducciones como la Biblioteca Compostela de la editorial Galaxia o la colección Contemporánea de Rinoceronte Editora, especialmente por su apuesta fuerte por la traducción al gallego, no deja de ser un ejemplo de relación de poder su falta de información sobre la obra, sobre el autor o la autora en las ediciones, así como sobre el hecho de que son traducciones (en el caso de la primera editorial, cuando se utiliza una lengua puente, no siempre se indica, y el nombre de la traductora o traductor no siempre figura en la cubierta ni en la cubierta interior). ${ }^{12}$

Entrando ya en la propia presentación de las obras seleccionadas, dentro del ámbito editorial queremos destacar en primer lugar la colección As Literatas de Edicións Xerais de Galicia, dirigida por la escritora y feminista María

11. Iría en la línea de la investigación necesaria que reclama Luna Alonso: "Analizar la noción de jerarquía de los autores, textos, lenguas y culturas traducidas hacia nuestra lengua, aunque quizás sea muy precipitado adelantar un análisis en un periodo tan breve de la historia de la traducción, resulta una línea de investigación muy interesante dentro de los estudios teóricos sobre la traducción" (2007: 261).

12. Montero (en prensa) enmarca esta información dentro del concepto de "lealtad de la editorial hacia el autor del texto original", que no solo significa garantizarle al autor que se cite su nombre en un lugar visible, sino también que se pueda identificar su procedencia cultural a través de los peritextos, así como el texto que ha dado origen a la traducción, indicando el título, lugar, editorial y el año de la primera publicación, así como el texto puente y su autoría. La autora señala que esa lealtad se debería además dar en otras fases de la producción, y con respecto a la fase creativa de la traducción incide en el enriquecimiento estético e ideológico que dicho comportamiento leal puede tener. 
Xosé Queizán. Esta colección nació en el año 1999 y cuenta en la actualidad con 14 títulos de las siguientes autoras: K. Blixen, A. Carter, H. Correia, S. Drakulic, A. Dworkin, L. Jorge, A. Kristof, K. Mansfield, C. McCullers, T. Mercado, H. Müller, E. Pardo Bazán, C. Perkins, J. Rhys y M. Yourcenar. La colección surge como apuesta por la traducción y la literatura (en este caso, prosa narrativa) escrita por mujeres con el objetivo de ofrecer un amplio abanico de modelos diversos de escritura. En este sentido, no es poco significativo el hecho de que en año 2007 se hiciese coincidir la publicación de dos títulos (Ancho mar de argazo, de Jean Rhys en traducción de Manuel Forcadela, y A voda, de C. McCullers en traducción de Laura Sáez) con el Día Internacional de la Mujer. Si observamos el catálogo de obras que componen la colección, se aprecia un importante punto de inflexión precisamente en ese año 2007: si bien los primeros títulos correspondieron en muchos casos a novelas cortas o recopilaciones de relatos y se utilizó como formato el libro de bolsillo, se cambia en ese momento a un formato mayor (parece así que las autoras saltan a primera "división") y a un nuevo perfil de traductoras y traductores. Además, este cambio no es seguramente ajeno a todas las mudanzas que en el sector editorial y de traducciones está viviendo la literatura gallega en los últimos años y que ya antes mencionamos. Todas las obras de la colección vienen acompañadas de un prólogo o introducción relativamente extenso, a veces de autoría de la traductora, así como de una presentación biobibliográfica de la autora y un texto de contracubierta que muchas veces es revelador. No es el caso de las publicaciones de H. Müller o A. Kristof, pero sí de Tununa Mercado, K. Mansfield, H. Correia o la recopilación de relatos de K. Blixen, C. Perkis y E. Pardo Bazán. Reproducimos a continuación parte del texto de la contracubierta de este último (Fenda, loucura e morte, 1999), de autoría de la directora de la colección, Queizán:

parte dun feito clave: a perda da virxindade, da pureza, considerada como valor supremo das mulleres, para seguir co matrimonio que, unha vez perdida esa integridade persoal, condena as mulleres á dependencia, ao infantilismo, á perda da confianza en si mesmas e, no peor dos casos, á morte. Nestes relatos encontramos unha crítica común a esta institución e á condición social das mulleres. Baixo esta perspectiva reunín e traducín estas catro historias que son catro pequenas obras mestras, cunha profunda precisión psicolóxica, que confrontan a política sexual e a problemática do matrimonio. Son magníficos documentos feministas.

Todas las obras recogidas en esta colección tienen un fuerte carácter de denuncia; uno de los últimos publicados (2005), Coma se non existise, de Slavenka Drakulic en traducción de Jairo Dorado, es un libro duro donde se relatan las atrocidades cometidas contra un grupo de mujeres internadas en 
un campo de concentración durante la guerra de Bosnia. En este caso no tomamos como ejemplo ningún epitexto, sino un extracto totalmente clarificador de la propia obra:

É noite. Tenta liberarse dos gardas. O bafo dos homes fede a augardente. A súa resistencia parécelles divertida, rin, coma se procurar fuxir fose gracioso. Nas súas mans é indefensa coma unha cativa. Aínda así revólvese, coma se aínda tivese esperanzas de fuxir.

Todas estamos contaminadas do mesmo polo campo, pensa. O noso sangue é impuro, todas somos iguais. As mulleres aquí son só como unha masa. Sen nome, sen face, substituíbeis coma un anaco de pan ou xabón. Existen só dúas categorías, as vellas e as novas. (Drakulic 2005: 61)

Pasamos a continuación a destacar algunos títulos publicados significativos, detrás de los que no resulta posible apreciar una política editorial determinada, sino un interés que intuimos que, en la mayor parte de los casos, es personal.

La traducción de The Awakening, de Kate Chopin, realizada por Ana María Valladares Fernández, fue publicada en papel en el año 2002 dentro de la colección de bolsillo Trasmontes de Toxosoutos, pero ya previamente se había publicado en Bivir, la Biblioteca Virtual ${ }^{13}$ un proyecto de la Asociación de Tradutores Galegos que promueve la normalización lingüística de Galicia en el campo de la traducción y que consiste en poner a disposición de las lectoras y lectores títulos clásicos -libres de derechos de autor/a- traducidos al gallego. Ninguna de las dos colecciones (ni la de Bivir ni la de Toxosoutos) incluye introducción ni prólogo ni presentación de la autora. Sin embargo, sí se destaca en la cubierta posterior del libro la relevancia de la obra dentro del feminismo:

Cando abrimos The Awakening, simplemente, espertamos a unha realidade que nos trae o cálido ambiente da Luisiana de fins do XIX, descubrimos as influencias acadianas, outro xeito de vivir, mergulladas no puritanismo dunha sociedade que reprime o papel da muller até convertela en obxecto, e non suxeito, evadida de calquera tipo de sensualidade, activa ou pasiva (...) A obra de Chopin pasou moitos anos barolecida no escuro galpón da necidade; mesmo así, non impide que anticipe un momento seminal da literatura americana, o camiño que, posteriormente, tomarían os neorrománticos do sur. Mais todo aquel mofo non abondou para impedir seu rescate, alá polos ' 60 do $\mathrm{XX}$, converténdose nunha das iconas do movemento feminista.

También dentro de esta colección ha visto la luz la traducción de otra mujer relevante en la literatura escrita por mujeres del XIX, como es Pardo Bazán. La traducción de Los pazos de Ulloa, realizada por Olga Patiño, se presenta

13. Puede consultarse en www.bivir.com. 
simplemente en la contracubierta como "paisaxe e a degradación dos personaxes de dúas Galicias en loita".

Retomamos Bivir para fijarnos especialmente en dos títulos, ambos traducidos por María Reimóndez: "O soño da sultana" y "A historia de Mary Prince" ${ }^{14}$ de Rokeya Sakhawat Hussain y Mary Prince, respectivamente. El primero de los textos está considerado como uno de los primeros ejemplos de ciencia ficción feminista, mientras que el segundo, con su subtítulo "unha escrava das Illas occidentais, contada por ela mesma", muestra claramente una intención de denuncia subyacente a la selección de la obra. También tenemos que destacar que en esta misma plataforma, Bivir, han sido publicadas las traducciones de Ana M. ${ }^{a}$ Valladares de varios relatos y novelas cortas de K. Mansfield.

De Sandra Cisneros contamos con dos obras traducidas, y en ambas el paratexto se centra en la fuerza de su voz y en la lectura de género que ofrece. Muller ceiba, el poemario Loose Woman (al que ya antes aludimos en referencia a las traducciones en publicaciones periódicas), fue publicado en el año 1997 dentro de la colección Ablativo Absoluto de Edicións Xerais y traducido por Marilar Aleixandre. La obra es presentada así en la contracubierta:

Explosiva e polémica, Muller ceiba é unha voz provocadoramente feminina, palabra erótica, humorística e mestiza que funde o made in América cos lagartos das lagoas do camiño a Yaxhilán, borrando para sempre a fronteira de Río Grande.

A casa de Mango Street fue publicada en el año 2008 por Rinoceronte dentro de la colección Contemporánea. Autora de la traducción es Alicia Meléndez Sousa. Como ya referimos, en esta colección no se incluyen metatextos de las traductoras ni introducciones, pero sí se presenta una breve biobibliografía de Cisneros en la solapa: "Na actualidade está considerada a mellor narradora chicana contemporánea, e o seu papel na literatura feminista é incuestionable", y dice así en la contracubierta: "A casa de Mango Street describe con breves pinceladas a situación socioeconómica da muller chicana nos Estados Unidos", donde además la presentan como un clásico, ya reconocido, de la novela de aprendizaje.

Las características de esta contribución hacen que por fuerza queden sin tratar autoras como Akhmátova, de quien Rinoceronte publicó en 2008 Só o silencio me responde, traducida del ruso por Ekaterina Guerbek y Penélope Pedreira, o como Héléne Cixous, de quien se publicó en el 2006 en versión

14. En el año 2008 le fue concedido el premio de traducción Plácido Castro, que se otorga entre los títulos publicados en Bivir. 
bilingüe la obra dramática A conquista da escola de Madhubai, con un extenso estudio introductorio de Purificación Cabido (autora también de la traducción). También significativa es la traducción en 1998 de Sabela Pato y Silvia Montero de Hier (Aquí), de la "Grande Dame" de la literatura alemana de posguerra, Hilde Domin. Sin embargo, no queremos dejar de nombrar a una autora con tanta influencia en el feminismo como Virgina Woolf, que en las tres traducciones al gallego publicadas ha recibido diferentes tratamientos. ${ }^{15}$ La primera traducción data del año 1993: se trata de Cara ó faro, publicada por Sotelo Blanco Edicións como número 3 de la Biblioteca de Traduccións. Los autores de la traducción son Manuela Palacios y Xavier Castro. Incluye un "Limiar" donde fundamentalmente se cuentan los vínculos que se establecen entre los personajes de la obra y la propia vida de Woolf, un breve apartado "Criterios de traducción" y notas de los traductores. Significativa es su presentación en la contraportada:

Cara ó faro pódese ler como unha metáfora das relacións entre os sexos. Excluídas dos xogos de poder, as mulleres están preparadas para participar nos mesmos por intermedio dos homes que as posúen: a socialización diferencial prepara os homes para ama-los xogos de poder, e as mulleres, para ama-los homes que participan neles.

Hasta el año 2004 no se vuelve a publicar nada de esta autora: en este caso se trata de As ondas, en la colección Clásicos Universais de Galaxia. No incluye ningún tipo de información en el peritexto y solo alguna nota de la traductora, que en esta ocasión es María Cuquejo. Un año después sale Un cuarto de seu, dentro de la colección As Letras das Mulleres, que analizamos en el siguiente apartado.

\section{La traducción institucional}

La edición de traducciones literarias en Galicia sigue dependiendo en buena medida de la política de subvenciones públicas y muchos de los títulos relacionados en el apartado anterior contaron con subvención. La gestación de las obras que recogemos bajo este epígrafe es, sin embargo, diferente: son traducciones que se venden específicamente como fruto de la colaboración entre una institución pública y una editorial. La presentación al público de estos títulos suele realizarse en el marco de un acto institucional, donde además del editor y el responsable de la edición está presente el político que corresponda (sea consejero de cultura, sea secretaria o secretario de política lingüística o de igualdad, quien además no pierde la ocasión de añadir un texto propio al

15. Sobre la recepción de Woolf en Galicia, vid. Palacios (1997) y Palacios y Ríos (2002). 
volumen en forma de "presentación"). En la mayor parte de los casos, este hecho afecta sin duda a la recepción de la obra por parte del mundo de la cultura. ${ }^{16}$

En relación con traducción y género, destacamos en este ámbito la colección As letras das mulleres, la Biblioteca de Teatro y la publicación de $O$ segundo sexo de Simone de Beauvoir.

La colección As letras das mulleres nació en el año 2004 y es fruto de la colaboración entre el Servizo Galego de Igualdade y la editorial Sotelo Blanco. La colección tiene por objetivo divulgar obras fundamentales, de ficción o ensayo, escritas por mujeres, y fomentar el reconocimiento de la labor intelectual con la que las mujeres han contribuido a la cultura universal a lo largo de la historia. A día de hoy (junio de 2010) incluye 12 títulos de las siguientes autoras: E. Wharton, A. Kollontai, Sofia Casanova, Aphra Behn, Olympe de Gouges, Rosalía de Castro, Emilia Pardo Bazán, Concepción Arenal, Jane Austen, Virgina Woolf, Mary Wollstonecraft y Cristina de Pizán. Todos los volúmenes cuentan con una presentación de la consejera o secretaria general, una introducción elaborada por una o un especialista del ámbito académico y, en alguna ocasión, una nota previa o aclaratoria de los traductores, que por ejemplo en el caso del título de Aphra Behn (traducida por Ramón Porto y Belén Souto) es verdaderamente extensa (entre otros aspectos, los traductores explican el difícil proceso de obtención del texto original, o decisiones tomadas a nivel léxico en la traducción, por ejemplo, la selección de "moinante" para "rover" en el título). A pesar de este espacio reservado para la voz de quien traduce, ${ }^{17}$ de cumplimiento con lo establecido en la Ley de Propiedad Intelectual (dejar constancia de a quien corresponden los derechos de autoría de la traducción) y con la práctica editorial habitual en Galicia de especificar el nombre de la traductora o traductor en la cubierta interior, la invisibilización a que están sometidos los traductores y traductoras se aprecia en que en la presentación de la colección, tanto en la página web de la institución

16. Luna Alonso señala además, acertadamente, que esta subvención puede funcionar como criba: "Al percibir el acto de traducción como una interpretación y una lectura cultural de un texto que pertenece a un espacio cultural distinto, se abre la puerta a una teoría de la traducción basada en la experiencia social de la desigualdad. Si el caso estudiado es el caso de una lengua minorizada, que pasa necesariamente por la prueba (o la censura) de la subvención, la experiencia es mucho más compleja" (2007: 261).

17. En algunos números también se incluyen notas, si bien el tratamiento es desigual y en algunos casos, denotando falta de profesionalidad o de saber editorial, ni se especifica que son notas de las traductoras. Así ocurre en A cidade das mulleres de Christine de Pisan (traducida por Susa Blanco; Sotelo Blanco 2004) o en Vindicación dos dereitos da muller de Mary Wollstonecraft (traducida por M. ${ }^{a}$ Fe González; Sotelo Blanco 2004). 
como de la editorial, no se especifica el nombre del autor o autora de la traducción..$^{18}$ Otra característica de la colección es que recoge tres volúmenes de autoras gallegas o españolas (Rosalía de Castro, Pardo Bazán y Concepción Arenal) en su lengua original, español, que nos hace cuestionarnos en qué medida es realmente necesario invertir tanto esfuerzo en recuperar textos de fácil acceso para el público gallego. No olvidemos además que, excepto en el caso de Virginia Woolf, Sofia Casanova y Alexandra Kollontai, los nueve títulos restantes, dada su antigüedad, están libres de derechos de traducción. La selección de títulos no deja de ser anecdótica, de interés histórico, pero no fundamental. No podemos evitar criticar este "esfuerzo económico" de la administración: quizás una edición más "modesta" (sin tapas duras, sin papel grueso ${ }^{19}$ ), un verdadero compromiso por el idioma gallego y por discursos contemporáneos (no históricos) y verdaderamente fundamentales del feminismo actual (necesarios en este contexto de llegada) podría haber dado cabida a una colección más necesaria como la deseada por González a propósito precisamente de esta serie:

A tradución das clásicas era unha das carencias pero non unha das urxencias para os discursos feministas en galego porque, á derradeira, podemos ler, e xa lemos, estes textos en diversas traducións ao español ou ao portugués. Non é que vaia unha cousa pola outra, pero se cadra cumpriría priorizar a tradución de textos menos arqueolóxicos e máis actuais e polémicos e non sempre dispoñibles nas linguas do noso contorno (por orde alfabética: Braidotti, Butler, Cixous, Collin, De Laurentis, Fuss, Haraway, Kaplan, Irigaray, Lorde, Mulvey, Rich, Sedgwick, Spivak...). Haberá quen diga que non se trata de elixir, mais de compatibilizar. Podo concordar con esta postura, pero, iso si, que ninguén crea que se paga a cota dos feminismos traducindo só textos de Simone de Beauvoir para atrás. A capacidade de intervención dun texto recuado no tempo, por importante que sexa, é limitada. E tanto o feminismo coma a cultura galegas precisan sumar lecturas e discusións coa contemporaneidade. (2004: 89-90)

Esta cita enlaza perfectamente con otro de los títulos traducidos fruto de la colaboración entre la Secretaría Xeral de Igualdade y Edicións Xerais: la traducción de O segundo sexo de Simone de Beauvoir, realizada por Marga Rodríguez Marcuño y con revisión conceptual de África López, y del que se han publicado dos volúmenes: el primero, en el año 2008, y el segundo, "A

18. Vid., respectivamente, http://sgi.xunta.es/publletr.html y http://www.soteloblanco edicions. com/narrativa .asp? Coleccion $=50$.

19. Y, sobre todo, sin usar en lo que sería el paratexto icónico -también representativo de la ideología- necesariamente colores tradicionalmente identificativos de lo "femenino" (rosa y lila). 
experiencia vivida", recientemente, en marzo de 2010. El libro se publica dentro de la colección Ensaio. Dado el carácter "semiinstitucional" de la publicación, cuenta de nuevo con unas palabras previas ("Adral") de la Secretaria Xeral de Igualdade. ${ }^{20} \mathrm{El}$ texto incluye numerosas notas de la traductora, que ella misma justifica en una sección previa titulada "Arredor da tradución galega" del primer volumen del modo siguiente: "debido a que este ensaio, como xa se mencionou, abrangue referencias a disciplinas moi variadas e, con frecuencia, dá por suposto coñecementos relativamente específicos e concretos, engadíronse algunhas notas da tradutora (N. da T.) co afán de facilitar a lectura" (Marcuño 2008: 28). ${ }^{21}$ Vemos de nuevo un esfuerzo por parte de todos los agentes participantes que, a pesar de su fuerte carga simbólica, no llega a cubrir verdaderas necesidades.

Un panorama distinto es el que presenta el teatro, un género que, en comparación incluso con el ensayo, resulta tener menor presencia en cuanto a repercusión dentro del sistema de llegada, si bien la escena gallega contemporánea es muy activa. Fruto de la colaboración entre la Escola Superior de Arte Dramática de Galicia (ESAD) y la Editorial Galaxia, con participación económica de la Xunta de Galicia, son las colecciones Biblioteca de Teatro y Biblioteca ESAD. En la primera de ellas, que es una colección de textos teóricos de referencia, se publica en el año 2009 Manual de práctica teatral feminista, de Elaine Aston en traducción de Laura Sáez, un libro que, además de servir de manual, pues sigue las fases de calentamiento, improvisación, escenificación y representación, es una reflexión sobre la historia del teatro y los discursos que se dan en él, entre ellos, el de la representación de la feminidad. En la segunda colección se recoge la Obra dramática completa de Sarah Kane, en edición y traducción del propio director de la ESAD, Manuel F. Vieites, que se presenta en la contraportada de este modo:

[...] Desta volta son as mulleres, entre elas Sarah Kane, que chegará a ser unha das autoras máis interesantes do panorama teatral en Europa. Malia a súa tráxica desaparición en 1999, a súa obra segue a ter unha fonda vixencia

20. El primer volumen se publicó en el año 2008, año en que Carme Adán ocupaba este cargo. El segundo volumen, "A experiencia vivida", a principios de 2010. En el intervalo se produjo un cambio de gobierno, y este segundo título ya no cuenta con "presentación institucional".

21. Con todo, una revisión de estas notas nos hace cuestionarnos hasta qué punto todas ellas son verdaderamente necesarias, como explicar quiénes son Rosa Luxemburgo o George Eliot (notas 106 y 107, respectivamente, del segundo volumen), o reproducir la traducción "literal" de las tres K de Hitler y hacer una propuesta alternativa (nota 106 del primer volumen) que, en un medio como una nota de la traductora, tendrá poca repercusión. 
e actualidade por mor deses mundos dominados pola dor e pola barbarie que tan ben soubo reflectir e que nos falan dun forte compromiso coa vida.

Ya recientemente, en 2010, se publica Catro pezas, de Caryl Churchill, de nuevo con amplio estudio introductorio y traducción del director de la escuela (hecho no poco significativo).

El teatro también ha servido para introducir una de las principales escritoras actuales europeas, Elfriede Jelinek. Xerais publicó en el año 2007 O que ocorreu despois de que Nora abandonara o seu home ou os piares das sociedades, en traducción de Susana Fernández y Franck Meyer, dentro de la colección Biblioteca Dramática Galega que realiza en colaboración con el Centro Dramático Galego, y cuyo catálogo está compuesto casi exclusivamente por producción propia. La editorial presenta la obra ${ }^{22}$ como heredera de la tradición de Ibsen y posible continuación de Casa de bonecas, publicada también por Xerais ese mismo año en traducción de Marta Dahlgren y Liliana Valado. Por las características de la colección no incluye lamentablemente notas ni introducción, aunque sí es significativa la presentación de la autora en las cubiertas: mientras en la solapa se indica en la breve biobibliografía de Jelinek "escritora austriaca comprometida co feminismo e a esquerda", en la contracubierta se presenta del modo siguiente: "A austríaca Elfriede Jelinek [...] é un dos autores (sic) contemporáneos máis importantes de fala alemá. Incansable feminista e defensora das ideas progresistas, a representación da súa obra teatral foi prohibida pola ultradereita en Austria".

\section{Voces de traductoras}

Aparte de la interesante relación traductora-escritora que pudimos ver en los apartados dedicados a las traducciones particulares y las traducciones en revistas de creación, no queremos dejar de hacer referencia en esta panorámica a aquellas voces de traductoras que, dentro de un entorno en el que sigue prevaleciendo la "invisibilidad" (bien por interés editorial, bien por desconocimiento de prácticas, bien por falta de conciencia de que la labor de quien traduce es un trabajo de autor/a), buscan y reclaman su espacio en los libros traducidos y actúan como iniciadoras de proyectos de traducción. El apartado será, por fuerza, breve debido a dos motivos: en primer lugar, el hecho de no constituir propiamente el objetivo de esta contribución y, en segundo lugar, la certeza de que la conciencia traductora y la escritura desde una postura de género bien merecen un análisis más detallado. Sobre este último punto

22. Vid.http://www.xerais.es/cgigeneral/newFichaProducto.pl?obrcod=1162319\&id_sello_ editorial_web=13\&id_sello_VisualizarDatos=13. 
simplemente queremos mencionar aquí la pugna ideológica entre traductora y editor que se generó a partir de la traducción de María Reimóndez de The Curious Incident of the Dog in the Night-Time, de Mark Haddon, una controversia que tuvo gran repercusión mediática y en la que se tomaron acciones de desprestigio de la traductora, ante las que ella, por otro lado, reaccionó con acciones judiciales. ${ }^{23}$

Retomando el hilo de lo anterior, además del trabajo de Queizán como iniciadora en la colección As Literatas y como traductora de algunos títulos, queremos señalar el trabajo de María Reimóndez y de Marilar Aleixandre.

Reimóndez pertenece a esas primeras promociones de la Licenciatura de Traducción e Interpretación de Vigo que demandaron y promovieron un cambio del perfil profesional de este colectivo en Galicia. ${ }^{24}$ Así, por ejemplo, en "A tradución dos teatriños", Reimóndez elabora un texto poético propio sobre su versión de Teatriños de Erín Moure y deja constancia además de una de sus líneas de investigación: ${ }^{25}$

No propio texto orixinal o galego non é só a lingua infiltrada en palabras ou fragmentos que nalgúns casos deixei marcados por cursivas, igual que no orixinal, senón que hai seccións completas (como a de "Homenaxes") nas que os textos aparecen en galego e inglés, traducións e retrotraducións. A súa función é tamén allear ás lectoras e lectores anglofalantes cun texto que non saben se ten relación co que entenden e que en moitos casos nin sequera saben en que lingua foi escrito. A pregunta de cal é o orixinal? quen lle dá ese status? que ou quen é a autora [...] son tamén preguntas que se fan no eido da tradución de forma constante e que os estudos posmodernos, feministas e poscoloniais deconstrúen para poñer de manifesto os actos de poder na tradución, tan frecuentemente invisibilizados pola falta de textos que expliquen a postura ou interpretación da tradutora, as razóns que levan a traducir certos libros e non outros, as ideoloxías que subxacen a todos estes actos. (Reimóndez 2007: 146)

Marilar Aleixandre, de la que ya hemos hablado en la sección de traducciones privadas y que en el año 2009, con motivo del Día Internacional de la Traducción, fue homenajeada por su labor como traductora literaria, crea un texto

23. Véase al respecto Castro 2009 y Reimóndez 2009.

24. Junto con Lara Santos y Saleta Fernández, también licenciadas de esa primera promoción, es socia co-fundadora de la Asociación Galega de Profesionais da Tradución e da Interpretación.

25. Reimóndez investiga sobre la relación que se establece entre traducción, feminismos y poscolonialismo, y lo hace en parte dentro del feminario de investigación "Feminismos e Resistencias. (Teorías e Prácticas)" de la Universidad de Vigo. Dentro de este grupo y del grupo de paratraducción de la misma universidad se encuadra el trabajo de Olga Castro sobre lenguaje no sexista y traducción. 
poético en su justificación de la traducción de Cisneros, en el que además de reflexionar sobre la dificultad de la decisión ["Eis o terceiro, esta Loose Woman, Muller Ceiba, pero tamén licenciosa, descarada, inconexa, desganduxada e libre, libre, Libre. Como ha ser por veces a tradución (loose translation). ¡Ah, a doce traición de traducir, a indecisión da escolla!" (1994: 5)], establece un vínculo entre la autora del original y la cultura de llegada:

Cantas espirais nos poemas desta Muller Ceiba que sen embargo nunca estivo en Galicia nin puido ver os petroglifos, a espiral de pedra como unha frecha enrodelada apuntando ó centro do universo (...) Cantas cobras serpentes, cantas cobras nos poemas. Pero Sandra Cisneros nunca estivo en Galicia, nin sabe que os poemas teñen cobras, nin debeu oír a Afonso X "e querom'oimais guardar do alacrán" advertirnos do alacrán negro ou veiro que pode deitar unha espiña no corazón, antes de facerlle eco no seu poema de alerta el alacrán güero"). (Aleixandre 1994: 6-7)

\section{Recepción}

La recepción de la traducción en Galicia se enmarca en un panorama en el que el discurso crítico sobre la traducción (hecho desde la traducción) aún tiene muy poca presencia. Así lo destacan Luna y Montero:

Unha presenza visible da crítica tradutiva que chegase a todos e todas non só conlevaría unha maior sensibilidade por parte do sector editorial e do público en xeral; senón que tamén repercutiría no comportamento dos axentes que interveñen dunha maneira ou doutra na elaboración do produto, desencadeando un efecto holístico. Unha maior presenza nos xornais ou na televisión, por exemplo, e mesmo nas librarías, debería significar un aumento da actividade lectora (promoción e venda). Queda pendente pois, a promoción interna e así mesmo a exteriorización dos propios textos, unha faceta na que as editoriais aínda non contaron co necesario apoio da Administración autonómica ou cos medios de comunicación en xeral. (Luna y Montero 2006: 16)

La prensa y las publicaciones periódicas especializadas se hacen eco de las novedades traducidas, centrándose a menudo en la descripción y argumento de la obra antes que en el proceso de traducción que, en caso de mencionarse, se limita a alguna observación sobre la fluidez de la lectura del texto de llegada. En numerosas ocasiones las críticas evidencian prejuicios patriarcales mediante la legitimación de determinadas traducciones echando mano de valores ajenos a ellas. Un caso significativo lo encontramos en el siguiente comentario sobre la versión gallega de Emily Dickinson, de quien se dice que "en máis dunha ocasión se ten comparado con Rosalía" (Constela 2004: 172). Otras veces nos encontramos delante de una crítica militante que tiende a magnificar el valor de una traducción, considerando, por ejemplo, $O$ segundo sexo como "unha obra de obrigada visita" (López Souto 2008), a denunciar 
carencias o a resaltar el valor de determinadas voces como modelos productivos en nuestro sistema literario.

La práctica inexistencia de una crítica especializada en la traducción es un hecho que todavía hoy se puede constatar en el contexto de un oficio caracterizado por el voluntarismo, la falta de profesionalización (no por falta de profesionales, sino por falta de apuesta más clara del sector editorial por estas y estos profesionales) y la dispersión.

\section{Conclusiones}

Una aproximación al estudio de la traducción literaria desde el prisma del género supone, como ha quedado demostrado, la exploración de territorios vastos, como el feminismo, la traductología o la historia de la traducción, de reciente incorporación a nuestro sistema literario. La escasez de materiales de estudio ha obligado, por otra parte, a desplazar el foco de atención en no pocas ocasiones a elementos marginales, como es el caso de los paratextos.

Otra de las evidencias que nuestro trabajo pone de manifiesto es la relación entre la historia de la traducción -también a la luz del género- y los avatares políticos y sociolingüísticos. Estas particulares circunstancias explican que hayamos tenido que recurrir a materiales poco frecuentes a la hora de elaborar una tipología de traducciones singular que consideramos una de las mayores aportaciones de nuestro trabajo, y que distingue traducciones privadas, traducciones difundidas en publicaciones periódicas, traducción editorial y traducción institucional.

De nuestro análisis se concluye también cómo la posibilidad de acceder a un importante número de obras literarias desde el castellano -no tanto, por falta de hábito y también de voluntad política, del portugués- explica en buena medida el hecho de que el público no haya sentido, en general, la necesidad de una traducción al gallego. La baja demanda está también ligada a la falta de costumbre de leer en gallego por parte de las generaciones de más edad debido a la herencia de un sistema educativo centralista. No obstante, cada vez son más los lectores concienciados, educados muchos de ellos ya al amparo de la Ley de Normalización Lingüística, para los que la lectura en gallego es una práctica normal. Ante este panorama, las instituciones públicas tienen todavía una importante responsabilidad a la hora de apoyar con políticas específicas la traducción al gallego.

La reivindicación de la lectura de "los clásicos" de la literatura universal en versión gallega resulta comprensible no solo por la nueva interpretación que toda traducción comporta, sino también, en este caso, por la necesidad de reafirmar la independencia del sistema literario gallego con respecto al 
español. Con todo, creemos necesario replantear la configuración de nuestro canon, cuestión que ha sido planteada ya por Luna y Montero al explicar que

a cultura minorizada en situación diglósica adoita configurar un canon na lingua propia, mesmo complementario ao da cultura coa que convive precisamente por razóns de prestixio. Con todo, cabe cuestionar a necesidade de importar todo o canon establecido. Se cadra, é máis importante traducir textos innovadores e ausentes no polisistema. (Luna y Montero 2006: 18)

La falta de planificación sigue siendo hoy en día uno de los principales problemas de la traducción al gallego. En una buena parte de los casos, las traducciones publicadas han visto la luz gracias al interés personal o en función de la capacidad de los directores de las colecciones o de personas próximas a ellos con dominio de la lengua de origen. Esto se aprecia a todos los niveles, pero particularmente en las traducciones aparecidas en publicaciones periódicas, donde es posible además identificar algunas tendencias que pueden ser estudiadas en paralelo al desarrollo de determinadas tipologías textuales. El caso más claro es el de la poesía, donde muchas de las traducciones han construido cánones con los que han dialogado, por un lado, los poetas de los ochenta y, por otro, la escritura de género.

La traducción de escritoras se caracteriza además, como ya se ha apuntado, por la doble marginalidad derivada de la consideración tanto del oficio como del propio género. El análisis del caso gallego revela además un nuevo margen debido a la condición periférica y a la anormal historia de la cultura gallega, que ha propiciado un desarrollo acelerado en los últimos años y una asunción de la práctica de la traducción como una forma de militancia. Este tercer margen hizo además del oficio un objetivo estratégico, al tiempo que convirtió en verdaderos emblemas traducciones como los fragmentos del Ulysses de Joyce (publicados por Otero Pedrayo en 1926 -la primera traducción peninsular-), Traballo de campo, de Seamus Heaney (Vicente Araguas, 1996) o, para el caso que nos ocupa, O segundo sexo, de Simone de Beauvoir.

\section{Bibliografía}

AleixandRe, M. P. (1987) "Dous poemas de Sylvia Plath". Festa da palabra silenciada, 6. pp. 163-166.

AleiXAndre, Marilar. (1994) "Poemas de Sandra Cisneros". Festa da palabra silenciada, 10. p. 142.

AleiXANDRE, Marilar. (1997) "Escándalo, espiral". En: Cisneros, Sandra. 1997. Muller ceiba. Vigo: Edicións Xerais de Galicia.

AleiXANDRe, Marilar. (1999) Catálogo de velenos. Ferrol: Sociedad de Cultura Valle-Inclán. Col. Esquío. 
Armesto Faginas, Xosé Francisco. (1987) Cunqueiro: unha biografía. Vigo: Edicións Xerais de Galicia. $2^{\mathrm{a}}$ edición, 1991.

BeAuvolr, Simone de. (2008) O segundo sexo I. Os feitos e os mitos. Trad. de Marga Rodríguez Marcuño. Vigo: Edicións Xerais.

BEAuvolr, Simone de. (2010). O segundo sexo II. A experiencia vivida. Trad. de Marga Rodríguez Marcuño. Vigo: Edicións Xerais.

Blanco, Carmen. (1995) O contradiscurso das mulleres. Historia do feminismo. Vigo: Nigra.

Castro VÁzQuez, Olga. (2009) "El género (para)traducido: pugna ideológica en la traducción y paratraducción de $O$ curioso incidente do can á media noite". Quaderns 16. pp. 251-264. También en línea: ddd.uab.cat/pub/ quaderns/11385790n16p251.pdf.

Cisneros, Sandra. (1997) Muller ceiba. Trad. de M. Aleixandre. Vigo: Edicións Xerais de Galicia.

Cisneros, Sandra. (2008) A casa de Mango Street. Trad. de Alicia Meléndez Sousa. Cangas: Rinoceronte Editora.

Constela Bergueiro, Gonzalo. (2004) "Ollando cara adiante sen ira. Panorámica das traducións literarias ao galego no ano 2004". Anuario Grial de Estudios Galegos 2004. pp. 167-174.

DrAKUlic, Slavenka. (2005) Coma se non existise. Trad. de Jairo Dorado. Vigo: Edicións Xerais.

Garrido Vilariño, Xoán Manuel. (2005) “Texto e paratexto. Tradución e Paratradución". Viceversa 9-10. pp. 31-39.

GenetTe, Gérard. (1987) Seuils. Paris: Du Seuil.

Gómez Clemente, Xosé María. (2009) "Traducción al gallego". En: Lafarga, F. \& L. Pegenaute (eds.) 2009. Diccionario histórico de la traducción en España. Madrid: Gredos. pp. 436-442.

GONZÁLEZ, Helena. (2004). "Dúas clásicas feministas en galego: ¿intervención ou arqueoloxía?" Grial 164.

GONZÁlEZ LiAÑO, Iria. (2001-2002) "Traducción e xénero. O feminismo de Rosalía de Castro traducido ó inglés”. Viceversa 7-8. pp. 109-130.

JELINEK, Elfriede. (2006) O que ocorreu despois de que Nora abandonara o seu home ou os piares das sociedades. Trad. de Susana Fernández y Franck Meyer. Vigo: Edicións Xerais.

KAnE, Sarah. (2009) Obra dramática completa. Trad. por Manuel F. Vieites. Vigo: Editorial Galaxia.

LÓPEZ SOUTO, África. (2008). "O segundo sexo: unha obra de obrigada visita". Festa da palabra silenciada 24. pp. 144-147.

LunA Alonso, Ana. (2006) "Reedicións que saben a novo e novas edicións. A tradución cara ao galego en 2005”. Anuario Grial de Estudos Literarios Galegos (2005). pp. 191-198. 
Luna Alonso, Ana \& Silvia Montero Küpper. (2006) "Aspectos paratradutivos e políticas editoriais de literatura infantil e xuvenil traducida". En: Luna Alonso, Ana \& Silvia Montero Küpper (eds.) 2006. Tradución e política editorial de literatura infantil e xuvenil. Vigo: Servizo de Publicacións da Universidade de Vigo. pp. 11-23.

LunA AlONSO, Ana. (2007) "Historia reciente de la traducción literaria al gallego". En: Santoyo, J. C. \& J. J. Lanero (coords.) 2007. Estudios de traducción y recepción. León: Servicio de Publicaciones de la Universidad de León. pp.249-263.

María do CeBreiro. (2008) Cuarto de outono. Santiago: Sotelo Blanco.

MONTERo KÜPPER, Silvia. (en prensa) "Quality and Loyalty of Publishers: Galician Literature Translation Peritexts (2000-2009)". En: Luna Alonso, Ana; Silvia Montero Küpper \& Liliana Valado (eds.). Translation Quality Assessment Policies from Galicia.

MOURE, Teresa. (2007) Benquerida catástrofe. Vigo: Xerais.

TREGEBOV, Rhea. (1991) "Unhas notas introductoras sobre a literatura canadiana". Festa da palabra silenciada 8. pp. 134-141.

PALACIOS GONZÁLEZ, Manuela. (1997) "Some considerations on the translation of Virginia Woolf's To the Lighthouse into Galician”. En: Moskowich-Spiegel Fandiño, Isabel et alii (coords.). 1997. Some Sundry Wits Gathered Together. A Coruña: Servicio de Publicacións da Universidade da Coruña. pp. 177-181.

Palacios GonzÁlez, Manuela; Ríos Fernández, Carmen (2002): "Virginia Woolf no feminismo galego". En: Lorenzo, Ramón (coord.) 2002. Homenaxe a Fernando R. Tato Plaza. Santiago de Compostela: Servizo de Publicacións da Universidade de Santiago de Compostela. pp. 697-704.

PATO, Chus. (2004) Charenton. Vigo: Xerais.

QueIzÁn, María Xosé. (1994) Fóra de min. Vigo: Sons Galiza. Col. Xanela de Poesía.

Reimóndez Meilán, María. (2007) "A tradución dos teatriños". En: Moure, Erín. 2007. Teatriños ou aturuxos calados. Vigo: Galaxia. pp. 145-147.

Reimóndez MeIlÁn, María. (2009) "The Curious Incident of Feminist Translation in Galicia: Courtcases, Lies and Gendern@tions”. Galicia 21, A ‘09.pp. 68-89. En línea: www.galicia21journal.org/A/pdf/galicia21_6_reimondez.pdf.

RomAní, Ana (1994) Das últimas mareas. A Coruña: Espiral Maior.

Romaní, Ana. (2010) Laudatio a Marilar Aleixandre. Asociación de Escritores en Lingua Galega. En línea: http://www.aelg.org/resources/fckfiles/file/ laudatio_marilar_romani.pdf

SAlgado, Daniel. (2004) "Adrienne Rich: De dentes contra o imperio". A trabe de ouro 60. pp. 79-83.

VALADO, Liliana. (2008) "Quen traduce en Galicia? A importancia da tradución para a nosa industria editorial". Praza das Letras 5. pp. 10-13. 
VON FlOTOW, Luise. (1997) Translation and Gender. Translating in the 'Era of Feminism'. Manchester/Ottawa: St. Jerome/University of Ottawa Press.

VV. AA. (1999) FENDA, loucura e morte. Trad. de M. ${ }^{a}$ Xosé Queizán. Vigo: Edicións Xerais. 